\title{
Relay Kontrol Menggunakan Google Firebase dan NodeMCU pada Sistem Smart Home
}

\author{
Basri $^{1}$ \\ Akhmad Qashlim² \\ Suryadi ${ }^{3}$ \\ Program Studi Teknik Informatika, Universitas Al Asyariah Mandar ${ }^{1,2}$, Program Studi Sistem \\ Informasi Universitas Al Asyariah Mandar, \\ Polewali Mandar, Indonesia ${ }^{1,2,3}$ \\ E-mail:basri@unasman.ac.id ${ }^{1}$;qashlim@unasman.ac.id ${ }^{2}$; suryadiakib31@gmail.com $^{3}$
}

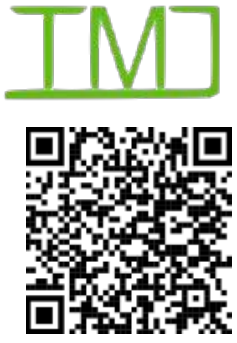

Notifikasi Penulis

01 Desember 2020

Akhir Revisi

10 Januari 2021

Terbit

01 Agustus 2021

Basri, B., Akhmad Qashlim, \& Suryadi. (2021). Relay Kontrol Menggunakan Google Firebase dan Node MCU pada Sistem Smart Home. Technomedia Journal, 6(1 Agustus).

https://doi.org/10.33050/tmj.v6i01 Agustus.1432

\section{ABSTRAK}

Penggunaan energi di rumah tangga yang tepat mempunyai manfaat yang banyak, bukan hanya bagi pemilik rumah akan tetapi dengan hemat energi dapat bermanfaat bagi kehidupan manusia. Permasalahan yang terjadi, terkadang manusia lupa dalam mematikan alat-alat elektroniknya sebelum berangkat kerja seperti Setrika, Ac, Tv, Kipas Angin, Rice Cooker, Dispenser, dan lain-lain. Sehingga akibatnya selain masalah keamanan juga dapat mengakibatkan pemborosan energi hingga pada banyaknya tagihan listrik. Pada penelitian ini telah di buat alat Alat dan Sistem Rumah Pintar yang di rancang dapat Mengontrol nyala Lampu dan peralatan elektronik lainnya menggunakan NodeMCU yang sudah terintegrasi Chip Wi-fi agar dapat dikontrol oleh Smartphone dimanapun selama ada akses internet. Hasil yang diperoleh dari pengujian ini adalah pengontrolan penuh atas mati atau menyalanya beberapa perangkat elektronik menggunakan perangkat android yang terhubung ke internet, sehingga pemilik rumah tidak perlu repot lagi kembali kerumah untuk mematikan peralatan elektroniknya.

Kata kunci : NodeMCU, Chip Wi-fi, Smartphone

\section{ABSTRACT}

The proper use of energy in the household has many benefits, not only for homeowners but saving energy can benefit human life. The problems that occur, sometimes people forget to turn off their electronic devices before leaving for work such as irons, air conditioners, TVs, fans, rice cookers, dispensers, and others. So that the consequence is that in addition to security issues, it can also lead to a waste of energy on the number of electricity bills. In this research, Smart Home Tools and Systems were designed to be able to control the lights and other electronic equipment using NodeMCU which has been integrated with a Wi-Fi chip so that it 
can be controlled by a Smartphone anywhere as long as there is internet access. The results obtained from this test were full control over the shutdown or turning on of several electronic devices using an android device connected to the internet so that homeowners don't have to bother returning home to turn off their electronic equipment.

Keywords: NodeMCU, Chip Wi-fi, Smartphone

\section{PENDAHULUAN}

Sebagian besar peralatan yang dibuat baik untuk keperluan rumah tangga dan perkantoran pemakaiannya menggunakan tenaga listrik. Kebutuhan akan tenaga listrik semakin meningkat sementara persediaan pasokan listrik sangat terbatas [1]. Hal tersebut menuntut kita untuk menghemat penggunaan listrik. Hemat penggunaan listrik berarti juga hemat biaya pembayaran listrik, apalagi semakin hari Tarif Dasar Listrik (TDL) semakin meningkat. Mulai 1 januari 2015 berlaku tariff adjustment sesuai Peraturan Menteri ESDM No.31 Tahun 2014. Tarif adjustment diberlakukan setiap bulan, menyesuaikan perubahan nilai tukar rupiah, harga bahan bakar dan inflasi bulanan [2]. Disisi lain perkembangan ponsel pintar dengan sistem operasi android yang mendominasi pasar ponsel dunia semakin banyak tersedia di pasaran dengan harga yang semakin terjangkau. Sistem operasi android sendiri bersifat sistem operasi open source yang dapat dimodifikasi sesuai kebutuhan. Sistem operasi open source yang ada pada ponsel pintar android memungkinkan untuk menghubungkan aplikasi dengan rangkaian mikrokontroler dan relay untuk mengendalikan lampu rumah dengan memanfaatkan realtime database gratis dari Google [3]. Sistem Smart home idealnya bukan hanya dalam hal otomatisasi, akan tetapi juga terintegrasi dengan sistem monitoring yang dapat memantau penghematan energi (Kumar, S., 2014). Konsep pengembangan smart home berbasis pengontrolan jarak jauh telah banyak dilakukan, khususnya perangkat-perangkat utama yang ada di sebuah rumah atau gedung (Salamah, I., 2020). Beberapa penelitian terkait konsep smart home yang telah diimplementasikan dalam sistem pengujian seperti oleh Kurnianto dengan riset tentang sistem kendali otomatis pada smart home menggunakan modul arduino uno [4]. Pada penelitian tersebut dikembangkan sistem otomatisasi dimana beberapa perangkat dasar di rumah tangga dapat menyala otomatis begitu pemilik rumah atau seseorang masuk ke dalam rumah tersebut (Kurnianto, dkk., 2016). Penelitian lainnya sebagaimana yang dilakukan oleh Arifin,S.,\& Fatoni, A. (2014) tentang pemanfaatan pulse width modulation untuk mengontrol motor (Studi Kasus Robot Otomatis Dua Devina), Mansyur, M. F.(2018) melakukan penelitian tentang rancangan bangun sistem kontrol otomatis pengatur suhu dan kelembaban kandang ayam broiler menggunakan arduino, Sutanto,H.(2012) melakukan penelitian tentang saklar dimmer 
lampu empat tahap filkom, Setiawan Iwan (2006) melakukan penelitian tentang programmable logic controller dan teknik perancangan sistem kontrol, Alamsyah, et all., (2015) melakukan penelitian tentang perancangan dan penerapan sistem kontrol peralatan elektronik jarak jauh berbasis Web, serta penelitian yang dilakukan oleh Kinasih, S. F. (2018) melakukan penelitian tentang pengontrolan ayunan bayi otomatis dengan mendeteksi sensor suara menggunakan mikrokontroler arduino [5]. Penggunaan sistem database open source sangat membantu dalam hal pengembangan sistem, Firebase sebagai platform google dalam berbagai penelitian digunakan dalam hal sistem Remote Config dan Realtime Database. Sistem realtime database dengan forebase tentunya sangat menunjang dengan banyaknya pengembangan sistem smart home yang terhubung dengan android [6]. Penelitian oleh Hartawan, dkk, dengan menguji kinerja firebase Realtime Database didapatkan hasil bahwa Firebase mendukung aplikasi IoT yang mampu memperbarui data secara waktu nyata, walaupun jenis koneksi jaringan yang digunakan memberikan efek penundaan yang bervariasi (Hartawan, dkk, 2019). Integrasi sistem sistem dengan mikrokontroler NodeMCU sebagai pengolah data selanjutnya mengirimkan data ke firebase realtime database, kemudian dengan sistem relay yang ada dalam mikrokontroller selanjutnya mengalirkan arus tegangan sebagai fungsi on/off pada perangkat yang terhubung. Realtime database memastikan monitoring dapat dilakukan secara online dengan sistem perangkat dan Interface Aplikasi dari firebase ke Aplikasi android yang telah dirancang sebelumnya sebagai interface monitoring dan controlling (Furqon, A., dkk., 2019). Penelitian tersebut menjadi ide dasar dalam mendesain konsep Smart Home berbasis pengontrolan jarak jauh dengan memanfaatkan Pengembangan Aplikasi Android. Konsep desain relay pada yang terhubung dengan mikrokontroler dan sistem jaringan pada penelitian sebelumnya juga menjadi dasar dalam pengembangn sistem yang diusulkan. Beberapa penelitian terdahulu sebagaimana yang disajikan di atas menggunakan sistem pengujian dengan control terbatas sebagaimana dilakukan dalam penelitian ini [7].

\section{PERMASALAHAN}

Berdasarkan hasil kajian penelitian terkait dan rumusan permasalahan yang diangkat dalam penelitian ini, maka beberapa rumusan permasalahan diantaranya:

1. Bagaimana merancang sistem kontrol nyala lampu dan peralatan elektronik lainnya menggunakan NodeMCU yang sudah terintegrasi Chip Wi-fi agar dapat dikontrol oleh Smartphone dimanapun selama ada akses internet.

2. Bagaimana situasi ideal yang dapat direkomendasikan dalam penerapan sistem 
relay kontrol yang diterapkan dalam penelitian ini.

\section{METODOLOGI PENELITIAN}

Penelitian ini menggunakan pendekatan studi eksperimen di laboratorium dengan menggunakan perangkat pendukung sebagai sistem pengujian [8]. Pengumpulan data yang dilakukan dengan cara mengambil data-data yang diperlukan dari literatur yang berkaitan dengan penyusunan laporan. Metode Observasi dilakukan sebagai metode pengumpulan data yang dilakukan dengan cara melakukan pengamatan langsung di lapangan, mengenai kinerja dari perangkat yang digunakan. Pengujian relay dalam sistem yang dirancang dilakukan sebanyak lima kali untuk memastikan sistem dapat berjalan dengan baik [9].

\section{A. Kerangka Sistem}

Penjelasan mengenai kerangka sistem tersebut ialah perintah yang diberikan oleh User melalui smartphone android akan terintegrasi dengan Google Firebase Google Database untuk berinteraksi dengan Microcontroller NodeMCU menggunakan bantuan modul Esp 8266 terhubung ke internet (Wifi) untuk memerintahkan Relay menyalakan dan mematikan aliran listrik berbasis 220V. Desain kerangka sistem yang dikerjakan dalam penelitian ini sebagaimana ditunjukkan pada Gambar 1.

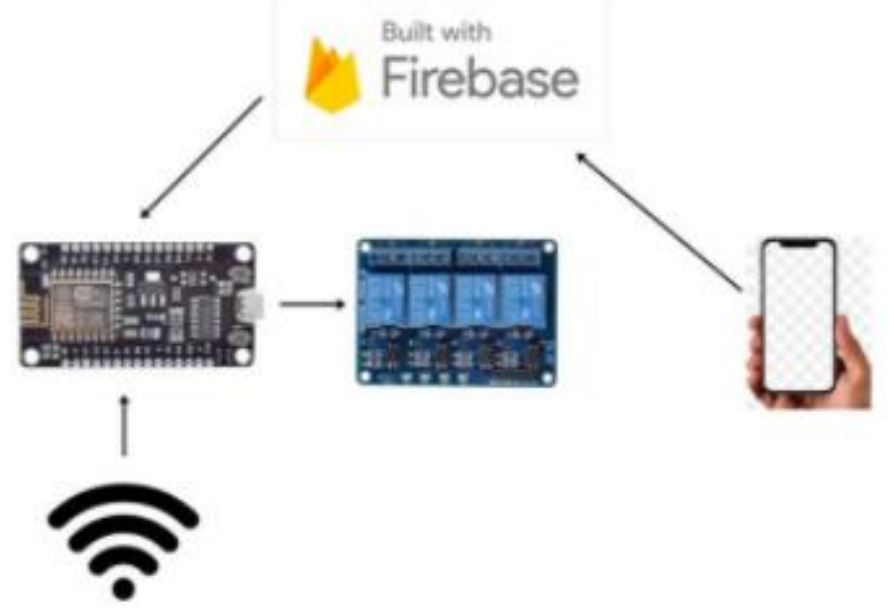

Gambar 1. Kerangka Sistem

B. Analisis dan Desain Sistem

Analisis dan desain sistem di atas menunjukkan proses pada saat kontrol yang dilakukan masuk ke sistem lalu dilanjutkan proses inisialisasi perintah on dan off kemudian aplikasi akan mengecek perintah inputan hingga proses perintah dilaksanakan [10]. Analisis dan desain sistem pada Smartphone Android yang terhubung ke sistem relay sebagaimana ditunjukkan pada Gambar 2. 


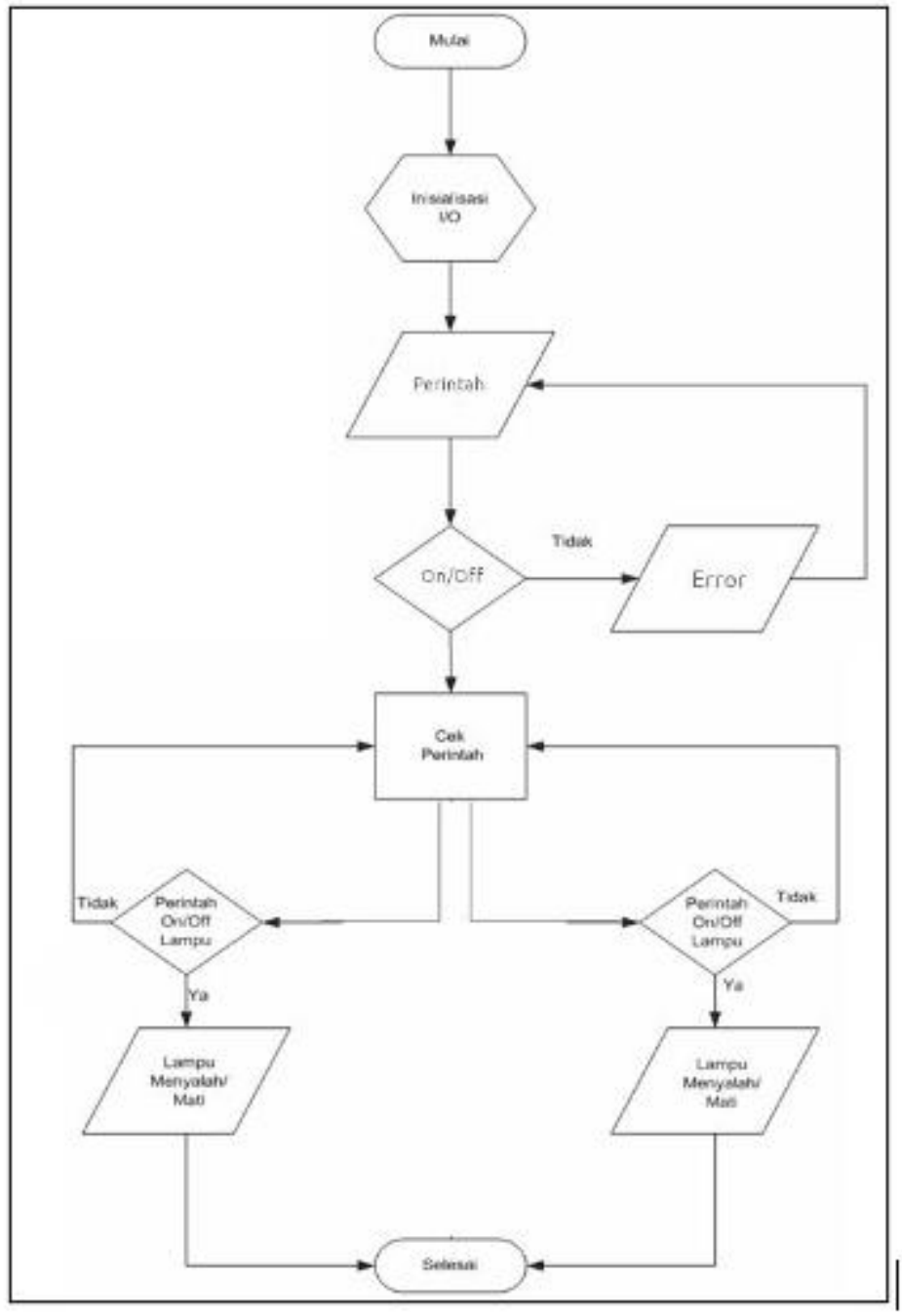

Gambar 2. Analisis dan Desain Sistem

\section{HASIL DAN PEMBAHASAN}

C. Perancangan Alat

Dari hasil penelitian yang dilakukan maka berhasil dirancang sebuah Sistem menggunakan Board NodeMCU yang lebih canggih dari Arduino untuk relay kontrol berbasis iot menggunakan google firebase dan node mcu. Berikut gambar hasil perancangan alat. 


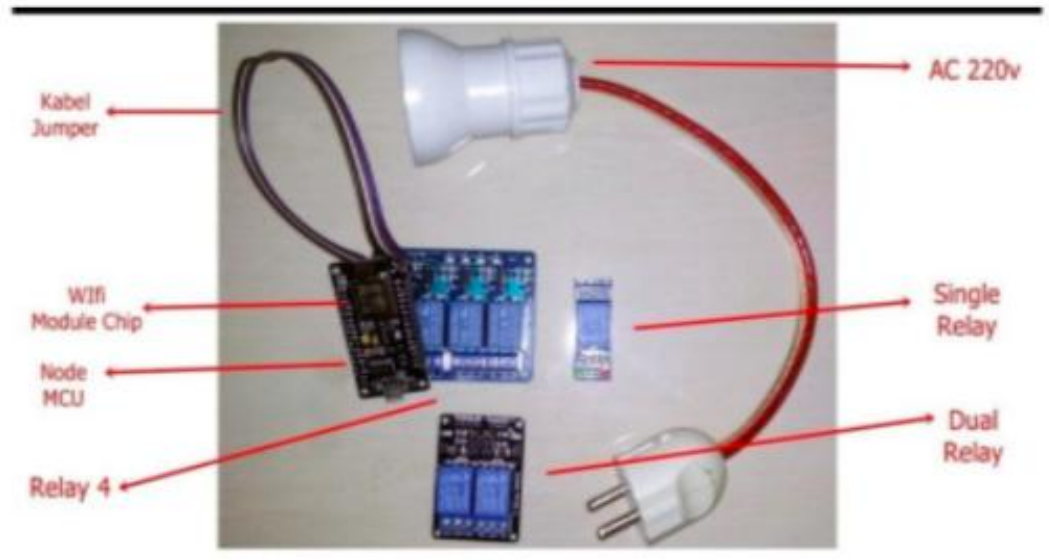

Gambar 3. Hasil Perancangan Alat

Gambar diatas menunjukkan alat Smart Home Control relay dengan Node MCU dan Blink secara jelas. Alat ini juga dilengkapi Akses Kontrol Menggunakan Smartphone Android untuk Kontrol jarak jauh [11].

Alat dan Sistem yang dirancang dapat mengontrol nyala lampu dan peralatan elektronik lainnya menggunakan Node MCU yang sudah terintegrasi Chip Wi-fi agar dapat dikontrol oleh Smartphone dimanapun selama ada akses internet [12]. NodeMCU cukup di koneksikan dengan bantuan software Arduino IDE sehingga dapat mengontrol relay jarak jauh, dan apabila NodeMCU telah terkoneksi oleh WIfi maka Smartphone akan dapat mengakses dan mematikan semua relay yang terhubung oleh Node MCU [13].

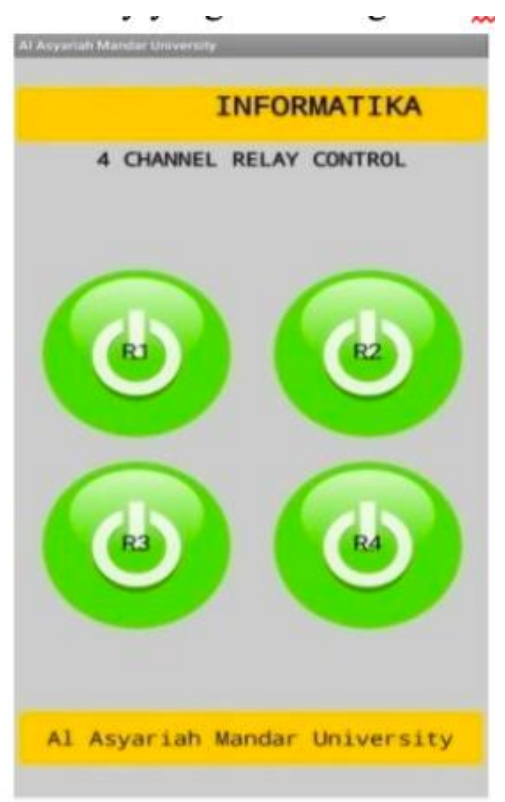

Gambar 4. Hasil Akhir Tampilan Aplikasi Kontrol Relay 


\section{Pengujian Sistem}

Pada tahapan pengujian sistem ini, yaitu pengujian fungsional untuk menguji kinerja sistem dan alat secara keseluruhan, pengujian ini berfokus pada fungsi-fungsi setiap perangkat yang telah dirancang dalam sistem yang dibangun [14]. Pengujian dengan menggunakan metode blackbox, yaitu pengujian yang tidak mengakomodir mekanisme internal pada sebuah sistem dan hanya berfokus pada keluaran yang dihasilkan sebagai respon dari pelaksanaan sebuah kondisi yang diinginkan pada pengujian [15]. Dalam pengujian ini diharapkan sistem dapat tanggap atas seluruh perintah yang telah dipersiapkan dan dapat langsung mengeksekusi perintah dari Smartphone pengguna [16]. Model pengujian kinerja perangkat dilakukan lebih awal dengan menggunakan Miniatur Smart Home dengan tetap menghubungkan perangkat dengan sistem jaringan internet [17]. Pengujian ini melibatkan empat channel control berupa lampu indikator pada perangkat relay dengan empat fungsi tombol pada Aplikasi android yang dirancang [18]. Simulasi relay control ditandai dengan penamaan D0 (Lampu Kamar), D1 (Lampu Dapur), D2 (AC Kamar), dan D3 (Kipas Angin). Pemberian nama tersebut disimulasikan sebagai perangkat elektronik yang umumnya terdapat pada rumah yang perlu untuk dimonitoring dalam penggunaannya [19].

Berikut hasil pengujian blackbox dengan 5 kondisi :

3. Pengujian pada relay control D0

Hasil pengujian pada relay control D0 akan ditunjunjukkan pada tabel 1. Tampilan relay control D0 yang berhasil diuji ditampilkan pada gambar 5 sebagai berikut : 
Tabel 1. Pengujian Relay control D0 (Lampu Kamar)

\begin{tabular}{|l|l|}
\hline \multicolumn{1}{|c|}{ Tindakan } & \multicolumn{1}{|c|}{ Keterangan } \\
\hline NodeMCU dan Smartphone (Blink) & $\begin{array}{l}\text { a. Node MCU Terkoneksi dengan Wifi dan } \\
\text { Server Database Firebase. } \\
\text { b. Smartphone Android Terkoneksi dengan Wifi } \\
\text { dan Server Database Firebase. } \\
\text { Data yang Diharapkan }\end{array}$ \\
$\begin{array}{l}\text { Relay control D0 (Lampu Kamar) dapat } \\
\text { dimatikan dan dinyalakan menggunakan } \\
\text { Smartphone. } \\
\text { Kengamatan }\end{array}$ & $\begin{array}{l}\text { Sesuai dengan system yang telah dibuat maka } \\
\text { NodeMCU Merespon perintah yang telah } \\
\text { ditanamkan di dalamnya, menyalakan dan } \\
\text { mematikan listrik pada perabot yang telah } \\
\text { dipasangi system ini secara realtime. } \\
\text { a. Pada Relay control D0 (Lampu Kamar) dapat } \\
\text { dinyalakan dengan sangat baik. } \\
\text { b. Relay pada Relay control D0 (Lampu Kamar) } \\
\text { dapat dimatikan dengan sangat baik, tapi } \\
\text { kadang dengan jeda beberapa detik saat } \\
\text { jaringan internet bermasalah. }\end{array}$ \\
\hline
\end{tabular}
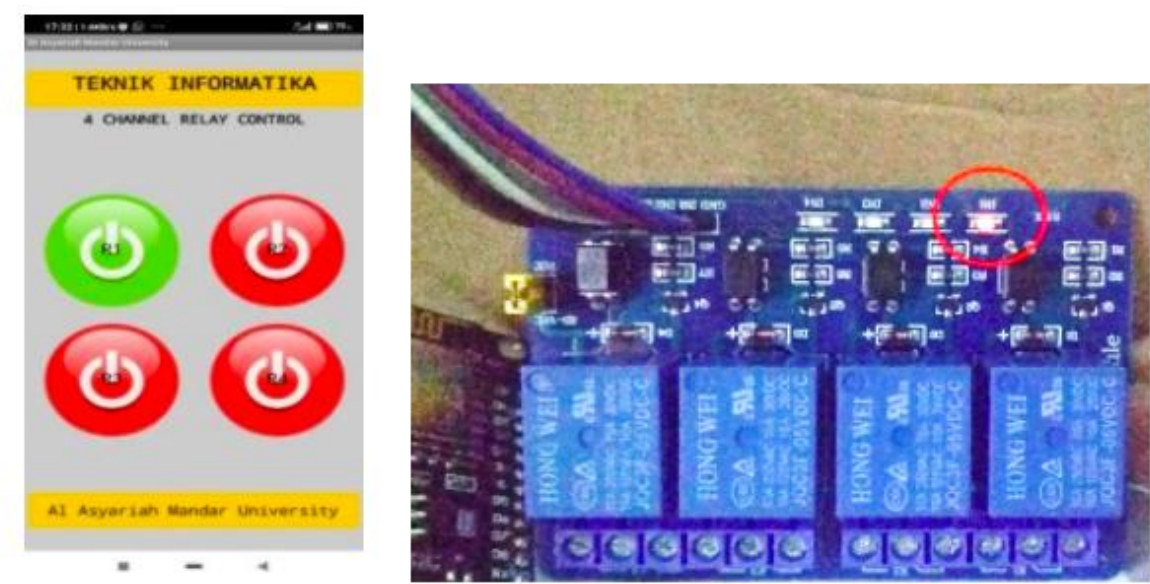

Gambar 5. Relay control D0 (Lampu Kamar) On pada Aplikasi dan Sistem 


\section{Pengujian pada relay control D1(Lampu Dapur)}

Hasil pengujian pada relay control D1 akan ditunjunjukkan pada tabel 2. Tampilan relay control D1 yang berhasil diuji ditampilkan pada gambar 6 sebagai berikut :

Tabel 2. Pengujian Relay control D1 (Lampu Dapur)

\begin{tabular}{|l|l|}
\hline \multicolumn{1}{|c|}{ Tindakan } & \multicolumn{1}{|c|}{ Keterangan } \\
\hline NodeMCU dan Smartphone (Blink) & $\begin{array}{c}\text { a. NodeMCU Terkoneksi dengan Wifi dan Server } \\
\text { Database Firebase } \\
\text { b. Smartphone Android Terkoneksi dengan Wifi } \\
\text { dan Server Database Firebase }\end{array}$ \\
Data yang Diharapkan & $\begin{array}{l}\text { Relay control D1 (Lampu Dapur) dapat dimatikan } \\
\text { dan dinyalakan menggunakan Smartphone } \\
\text { Pengamatan }\end{array}$ \\
$\begin{array}{l}\text { Sesuai dengan system yang telah dibuat maka } \\
\text { NodeMCU merespon perintah yang telah } \\
\text { ditanamkan di dalamnya, menyalakan dan } \\
\text { mematikan listrik pada perabot yang telah } \\
\text { dipasangi system ini secara realtime. } \\
\text { a. Relay pada D1 (Lampu Dapur) dapat dinyalakan } \\
\text { dengan sangat baik. } \\
\text { b. Relay pada D1 (Lampu Dapur) dapat dimatikan } \\
\text { dengan sangat baik, tapi kadang dengan jeda } \\
\text { beberapa detik saat jaringan internet bermasalah. }\end{array}$ \\
\hline
\end{tabular}
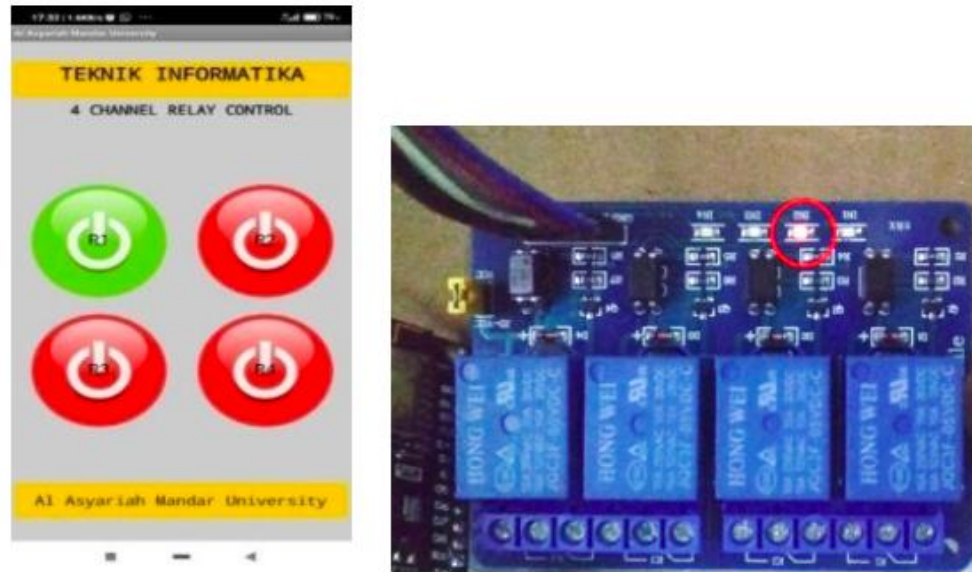

Gambar 6. Relay control D1 (Lampu Dapur) On pada Aplikasi dan Sistem

4. Pengujian pada relay control D2 (AC Kamar) 
Hasil pengujian pada relay control D2 akan ditunjunjukkan pada tabel 3. Tampilan relay control D2 yang berhasil diuji ditampilkan pada gambar 7 sebagai berikut :

Tabel 3. Pengujian Relay control D2 (AC Kamar)

\begin{tabular}{|c|c|}
\hline Tindakan & Keterangan \\
\hline NodeMCU dan Smartphone (Blink) & $\begin{array}{l}\text { a. NodeMCU Terkoneksi dengan Wifi dan } \\
\text { Server Database Firebase } \\
\text { b. Smartphone Android Terkoneksi dengan } \\
\text { Wifi dan Server Database Firebase }\end{array}$ \\
\hline Data yang Diharapkan & $\begin{array}{l}\text { Relay control D2 (AC Kamar) dapat dimatikan } \\
\text { dan dinyalakan menggunakan Smartphone }\end{array}$ \\
\hline Pengamatan & $\begin{array}{l}\text { Sesuai dengan system yang telah dibuat maka } \\
\text { NodeMCU Merespon perintah yang telah } \\
\text { ditanamkan di dalamnya, menyalakan dan } \\
\text { mematikan listrik pada perabot yang telah } \\
\text { dipasangi system ini secara realtime. }\end{array}$ \\
\hline Kesimpulan & $\begin{array}{l}\text { a. Relay D2 (AC Kamar) dapat dinyalakan } \\
\text { dengan sangat baik. } \\
\text { b. Relay D2 (AC Kamar) dapat dimatikan } \\
\text { dengan sangat baik, tapi kadang dengan jeda } \\
\text { beberapa detik saat jaringan internet } \\
\text { bermasalah. }\end{array}$ \\
\hline
\end{tabular}
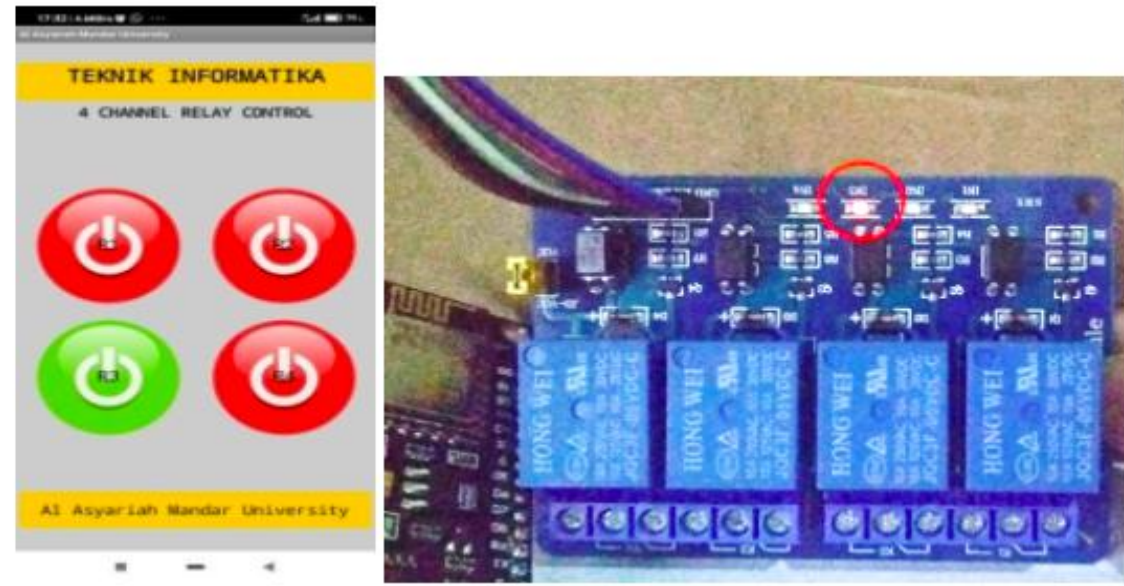

Gambar 7. Relay control D2 (AC Kamar) On pada Aplikasi dan Sistem 4. Pengujian pada relay control D3 (Kipas Angin) 
Hasil pengujian pada relay control D3 akan ditunjunjukkan pada tabel 4. Tampilan relay control D3 yang berhasil diuji ditampilkan pada gambar 8 sebagai berikut :

Tabel 4. Pengujian Relay control D3 (Kipas Angin)

\begin{tabular}{|l|l|}
\hline \multicolumn{1}{|c|}{ Tindakan } & \multicolumn{1}{|c|}{ Keterangan } \\
\hline NodeMCU dan Smartphone (Blink) & $\begin{array}{l}\text { a. NodeMCU Terkoneksi dengan Wifi dan } \\
\text { Server Database Firebase. } \\
\text { b. Smartphone Android Terkoneksi dengan Wifi } \\
\text { dan Server Database Firebase. }\end{array}$ \\
Pengamatan & $\begin{array}{l}\text { Relay control D3 (Kipas Angin) dapat dimatikan } \\
\text { dan dinyalakan menggunakan Smartphone } \\
\text { Sesuai dengan system yang telah dibuat maka } \\
\text { Kesimpulan }\end{array}$ \\
$\begin{array}{l}\text { NodeMCU Merespon perintah yang telah } \\
\text { ditanamkan di dalamnya, menyalakan dan } \\
\text { mematikan listrik pada perabot yang telah } \\
\text { dipasangi system ini secara realtime. } \\
\text { a. Relay control D3 (Kipas Angin) dapat } \\
\text { dinyalakan dengan sangat baik. } \\
\text { b. Relay control D3 (Kipas Angin) dapat } \\
\text { dimatikan dengan sangat baik, tapi kadang } \\
\text { dengan jeda beberapa detik saat jaringan } \\
\text { internet bermasalah. }\end{array}$ \\
\hline
\end{tabular}




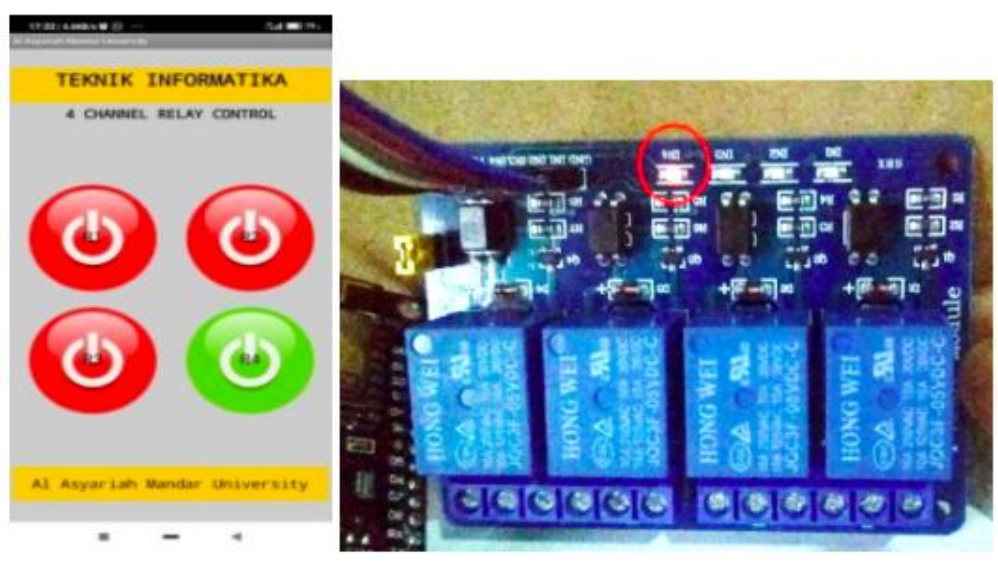

Gambar 8. Relay control D3 (Kipas Angin) On pada Aplikasi dan Sistem

5. Pengujian pada relay control bersamaan

Hasil pengujian pada relay control bersamaan akan ditunjunjukkan pada tabel 5 . Tampilan relay control bersamaan yang berhasil diuji ditampilkan pada gambar 9 sebagai berikut :

Tabel 5. Pengujian Semua Relay control Bersamaan

\begin{tabular}{|c|c|}
\hline Tindakan & Keterangan \\
\hline NodeMCU dan Smartphone (Blink) & $\begin{array}{l}\text { q. NodeMCU Terkoneksi dengan Wifi dan Server } \\
\text { Database Firebase. } \\
\text { r. Smartphone Android Terkoneksi dengan Wifi } \\
\text { dan Server Database Firebase. }\end{array}$ \\
\hline Data yang Diharapkan & $\begin{array}{l}\text { Semua Relay control D0, D1, D2, dan D3 dapat } \\
\text { dimatikan dan dinyalakan menggunakan } \\
\text { Smartphone. }\end{array}$ \\
\hline Pengamatan & $\begin{array}{l}\text { Sesuai dengan system yang telah dibuat maka } \\
\text { NodeMCU Merespon perintah yang telah } \\
\text { ditanamkan di dalamnya, menyalakan dan } \\
\text { mematikan listrik pada perabot yang telah dipasangi } \\
\text { system ini secara realtime. }\end{array}$ \\
\hline Kesimpulan & $\begin{array}{l}\text { s. Semua Relay control dapat dinyalakan secara } \\
\text { bersamaan dengan sangat baik. } \\
\text { t. Semua Relay control dapat di matikan secara } \\
\text { bersamaan dengan sangat baik. }\end{array}$ \\
\hline
\end{tabular}




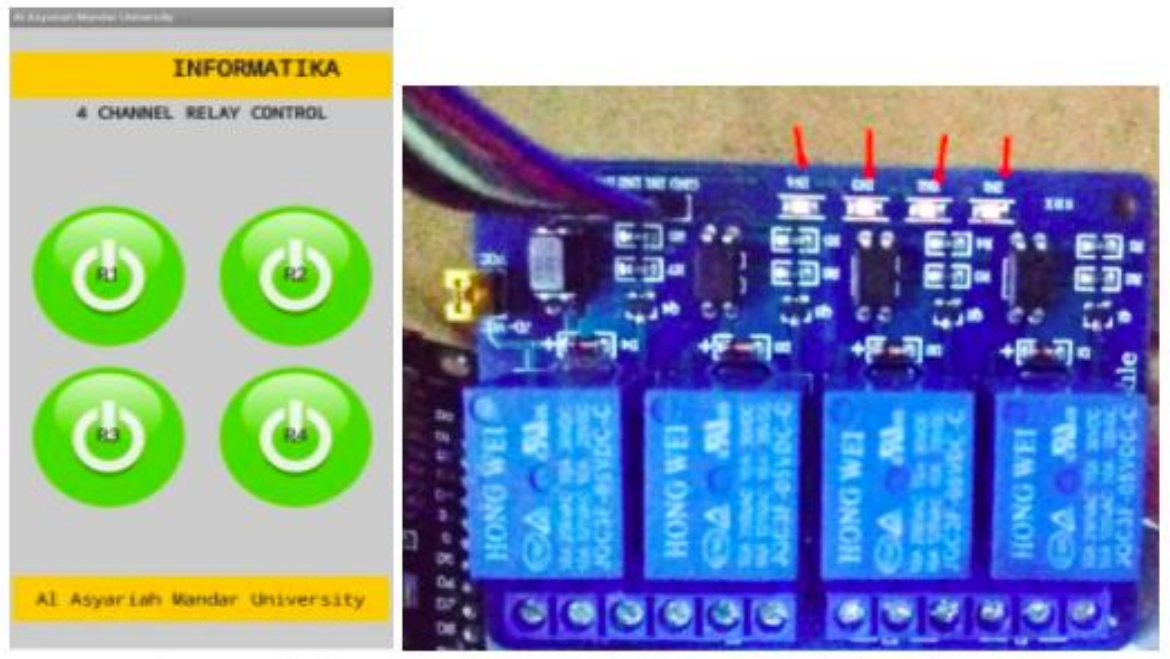

Gambar 9. Semua Relay control On pada Blink dan Sistem

\section{E. Pengujian Sistem}

Berdasarkan hasil pengujian pada relay control D0 sampai D3 dan pengujian pada relay control bersamaan dengan menggunakan metode blackbox, didapatkan hasil pengujian yang menunjukkan bahwa sistem berjalan dengan baik [20]. Node MCU menunjukkan dapat terkoneksi dengan baik terhadap sistem Wifi dan Server Database Firebase. Selain itu Smartphone Android Terkoneksi dengan Wifi dan Server Database Firebase. Pengujian dengan menyalakan dan mematikan listrik pada perangkat yang terhubung dengan sistem secara realtime berjalan dengan baik, walaupun pada beberapa kondisi terkendala dengan jaringan komputer yang kadang bermasalah. Secara umum perancangan sistem untuk relay control berbasis IOT menggunakan Google Firebase dan nodeMCU berjalan dengan baik karena alat dapat bekerja dan menjaga kestabilan selama pemakaian dan pengujian .

\section{KESIMPULAN}

Dari pembahasan dan analisis pada bab-bab sebelumnya, dapat disimpulkan bahwa Perancangan Sistem untuk Implementasi relay kontrol dengan konsep Smart Home yang dilakukan dalam penelitian ini menjadi salah satu konsep sistem berbasis Internet of Things (iot) menggunakan Google Firebase dan NodeMCU berjalan dengan baik karena alat dapat bekerja dan menjaga kestabilan selama pemakaian dan pengujian. Alat bekerja berdasarkan kendali aplikasi Smartphone yang sudah dibuat dengan cara mengirimkan logika 1 dan 0 pada NodeMCU menggunakan database Google Firebase sehingga akan mematikan dan 
menyalakan modul Relay. Jaringan Internet yang digunakan sangat berpengaruh terhadap kecepatan respon dari alat yang dibuat ini karena semakin kuat sinyal jaringan maka waktu tanggap atau waktu delay akan lebih cepat begitupun sebaliknya. Penggunaan Google Firebase dan NodeMCU sangat efektif dalam pengaplikasian Sistem Kontrol berbasis Internet. Penggunaan Arduino Uno dialihkan ke NodeMCU yang jauh lebih canggih sebab sistem sangat menguras Memory Flash Arduino, membuat kalibrasi alat menjadi lambat.

\section{SARAN}

Konsep Smart Home yang dikembangkan dalam penelitian ini sebatas pengujian sistem relay dengan pengembangan interface Aplikasi di Smartphone yang masih sederhana, sehingga untuk pengembangan yang lebih lanjut dapat di desain Interface Aplikasi yang lebih menarik untuk digunakan dengan menerapkan konsep pengembangan sistem berbasis Usability.

\section{DAFTAR PUSTAKA}

[1] A. A. Alamsyah and M. N. Faisal, "Perancangan Dan Penerapan Sistem Kontrol Peralatan Elektronik Jarak Jauh Berbasis Web," Jurnal Mekanikal, vol. 6, no. 2, pp. 577-584, 2015.

[2] S. Arifin and A. Fatoni, "Pemanfaatan Pulse Width Modulation Untuk Mengontrol Motor (Studi Kasus Robot Otomatis Dua Deviana)," Jurnal Ilmiah Teknologi dan Informasi ASIA, vol. 8, no. 2, 2014.

[3] I. Salamah, "Implementasi Smart Home Menggunakan Raspberry Pi Berbasis Android," Jurnal Teknik Elektro dan Komputer, vol. 9, no. 2, pp. 109-116, 2020.

[4] A. Furqon, A. B. Prasetijo, and E. D. Widianto, "Rancang Bangun Sistem Monitoring dan Kendali Daya Listrik pada Rumah Kos Menggunakan NodeMCU dan Firebase Berbasis Android," Techné: Jurnal IImiah Elektroteknika, vol. 18, no. 02, pp. 93-104, 2019.

[5] A. Setiadi, I. Handayani, and F. Fadilah, "Perancangan Aplikasi Fit Your Weight Untuk Menghitung Berat Badan Ideal Berbasis Android," Technomedia Journal, vol. 5, no. 2, pp. 144-154, 2021.

[6] S. Rahayu, A. Setiadi, and A. Muryanto, "Perancangan Sistem Pendaftaran Siswa Baru Secara Online Pada SMK Miftahul Jannah Cikupa," Technomedia Journal, vol. 5, no. 2, pp. 235-247, 2021.

[7] A. Maharani, S. Aninda, and S. Millah, "Pembuatan Kartu Ujian Online Sebagai Pengabdian Perguruan Tinggi," ADI Pengabdian Kepada Masyarakat, vol. 1, no. 2, pp. 8-14, 2021.

[8] R. Rosyid and M. A. W. Prasetyo, "Robot Peraga 12 Gerakan Pengaturan Lalu Lintas Berbasis Arduino Mega 2560," Technomedia Journal, vol. 5, no. 2, pp. 193-205, 2021.

[9] B. D. Wicaksono and S. Anggraeni, "Perancangan Website Sistem Informasi Transaksi Tagihan Layanan Purna Jual Properti Pada Pollux Properti Indonesia," TMJ (Technomedia Journal) Vol. 5 No. 2 Februari 2021, p. 132, 2021.

[10] N. Cholisoh, J. Junaidi, and I. S. Sari, "Rancangan Sistem Penginputan Judul Online 
KKP, TA/SKRIPSI Berbasis Laravel Pada Universitas Raharja," Technomedia Journal, vol. 5, no. 2, pp. 248-258, 2021.

[11] L. Sunarya, A. D. Purbayani, and N. Handayani, "Media Video Promosi Pada Roofpark Cafe \& Restaurant Pucak Bogor Jawa Barat," TMJ (Technomedia Journal) Vol. 5 No. 2 Februari 2021, p. 220, 2021.

[12] D. Cahyadi, A. Faturahman, H. Haryani, and E. Dolan, "BCS: Blockchain Smart Curriculum System for Verification Student Accreditation," International Journal of Cyber and IT Service Management, vol. 1, no. 1, pp. 65-83, 2021.

[13] L. Sunarya, B. Abdurachman, and P. R. Ningsih, "Video Profile Balai Latihan Kerja Pada Dinas Ketenagakerjaan Kota Tangerang," Technomedia Journal, vol. 5, no. 2, pp. 206-219, 2021.

[14] I. Muhamad, W. Hidayat, and I. Handayani, "Perancangan Sistem Informasi Persediaan Barang Pada PT. Pacific Paint Menggunakan PHP dan MySQL," Technomedia Journal, vol. 5, no. 2, pp. 182-192, 2021.

[15] Z. Fauziah, H. Latifah, X. Omar, A. Khoirunisa, and S. Millah, "Application of Blockchain Technology in Smart Contracts: A Systematic Literature Review," Aptisi Transactions on Technopreneurship (ATT), vol. 2, no. 2, pp. 160-166, 2020.

[16] A. Roihan, N. Rahayu, and D. S. Aji, "Perancangan Sistem Kehadiran Face Recognition Menggunakan Mikrokomputer Berbasis Internet of Things," Technomedia Journal, vol. 5, no. 2, pp. 155-166, 2021.

[17] L. Munaroh, Y. Amrozi, and R. A. Nurdian, "Pengukuran Risiko Keamanan Aset TI Menggunakan Metode FMEA dan Standar ISO/IEC 27001: 2013," Technomedia Journal, vol. 5, no. 2, pp. 167-181, 2021.

[18] I. Handayani, G. Maulani, E. Noviandri, and H. W. Ningsih, "Optimalisasi Sistem Pengelolaan E-Journal Berbasis Open Journal System (OJS) Menggunakan Framework CSS Bootstrap Pada Instansi dan Asosiasi," Technomedia Journal, vol. 5, no. 1 Agustus, pp. 106-117, 2020.

[19] A. S. Rafika, E. Febriyanto, and E. Safriyati, "Perancangan Modul Trainer Interface Mikrokontroler Berbasis ESP32 Sebagai Media Pembelajaran Pada Mata Kuliah Embedded System," Technomedia Journal, vol. 5, no. 1 Agustus, pp. 118-131, 2020.

[20] E. Febriyanto, T. Triyono, N. Rahayu, and R. Nurbaiti, "QRcode Verifikasi Sertifikat Sebagai Bukti Keabsahan Dokumen dalam Bidang Pendidikan," Technomedia Journal, vol. 5, no. 1 Agustus, pp. 96-105, 2020. 